\title{
SEISMIC BEHAVIOR OF ELEVATED WATER TANK
}

\author{
Nishigandha R. Patil ${ }^{1}$, Rajashekhar S. Talikoti ${ }^{2}$ \\ ${ }^{I}$ PG Student, Late G. N. Sapkal College of Engineering, Nashik, Maharashtra, India \\ ${ }^{2}$ Head of Department, Late G. N. Sapkal College of Engineering, Nashik, Maharashtra, India
}

\begin{abstract}
Hydrodynamic analysis of elevated water tank is a complex procedure involving fluid structure interaction. The elevated tank supports large water mass at the top of slender staging. In case of elevated tank the resistance against lateral forces exerted by earthquake is largely dependent of supporting system. Staging is considered to be a critical element as far as lateral resistance is concern. Satisfactory performance of staging during strong ground shaking is crucial. In this paper seismic behavior of elevated water tank in view point of their supporting system is evaluated using finite element software ETABS. The main objective is to evaluate a performance of different staging system for elevated water tank using finite element software ETABS. The spring mass model consisting of impulsive and convective masses as per IS 1893:2002 Part 2 has been used for the analysis. The parametric study is performed on mathematical model with different staging system to evaluate their performance with regard to lateral stiffness, displacement, time period, seismic base shear, overturning moment, flexure etc.
\end{abstract}

Keywords: Hydrodynamic analysis, Staging Performance, spring mass model, ETABS $* * *$

\section{INTRODUCTION}

Water tank is considered to be an important structure and they should remain functional during earthquakes to overcome the water demand due to fire etc. Water tanks are different from buildings, in the sense that a huge mass of water is concentrated at top supported on slender staging. This can be treated as an inverted pendulum representing a single degree of freedom system. The fair understanding of the behavior of tank during seismic activity is necessary in order to evaluate the forces exerted due to earthquake.

In general tanks are always partially filled with water and when they are subjected to horizontal seismic acceleration sloshing waves generates which exerts hydrodynamic forces on walls and base of tank. To calculate these hydrodynamic forces spring mass model suggested by IS 1893:2002 can be used. In case of elevated tank behavior of tank under hydrostatic and hydrodynamic forces is largely dependent on the staging configuration and its stiffness.

\section{METHODOLOGY}

In the present paper different alternative staging configuration for same water tank is studied with the help of ETABS analysis package. Spring mass idealization as per IS 1893:2002 has been used to evaluate the seismic base shear.

\subsection{Model Description}

$170 \mathrm{~m}^{3}$ capacity tank is selected for the study. Four models are prepared having different staging configurations. The other data used for the analysis is shown in table 1.

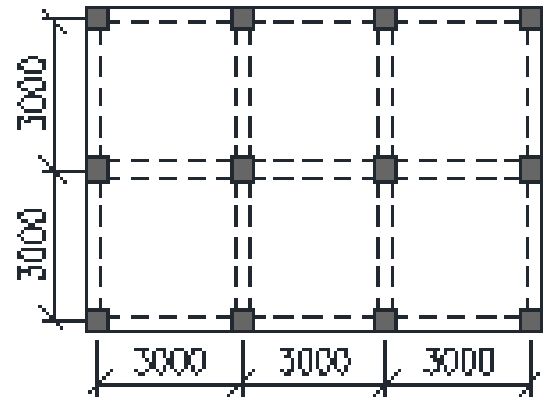

Fig -1: Model I(Plan)

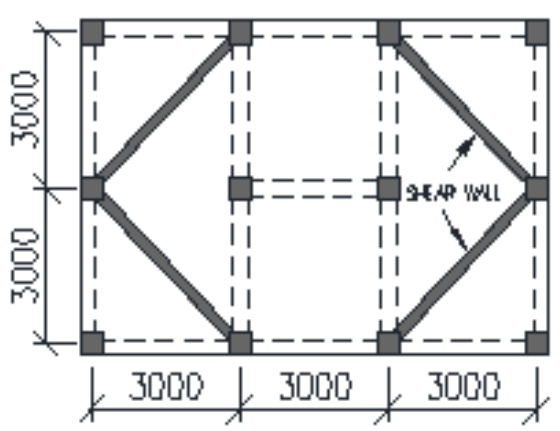

Fig -2: Model II(Plan) 


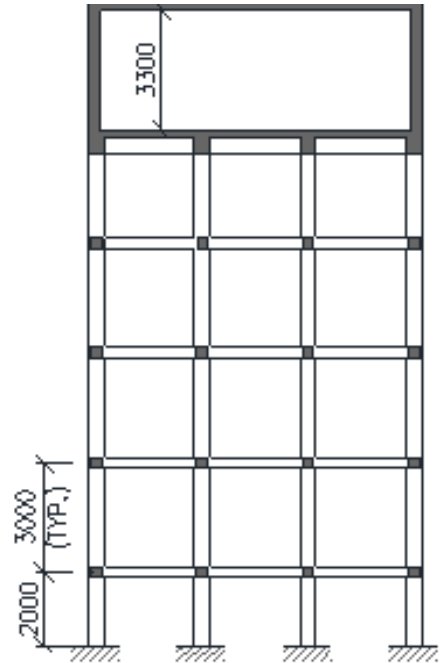

Fig -3: Model I(Elevation)

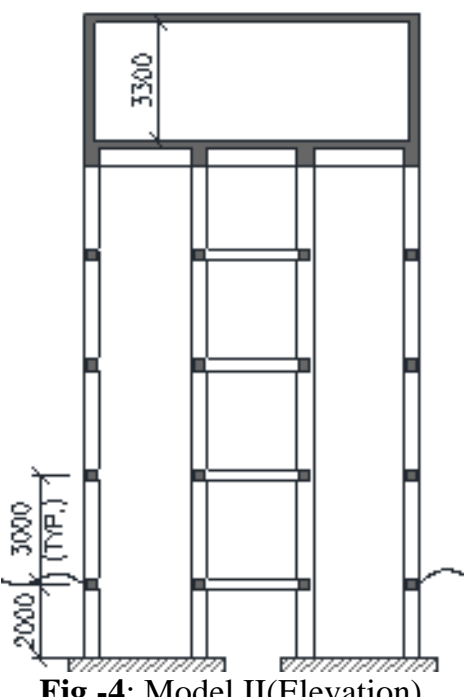

Fig -4: Model II(Elevation)

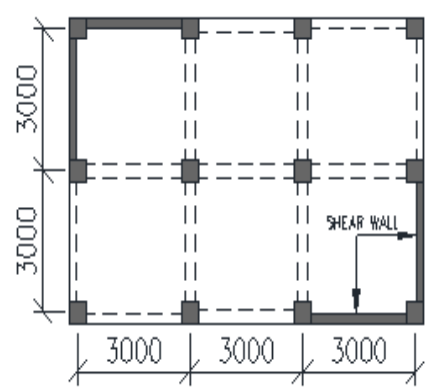

Fig -5: Model III(Plan)

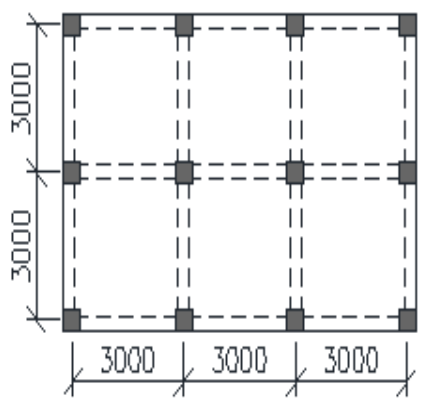

Fig -6: Model IV(Plan)

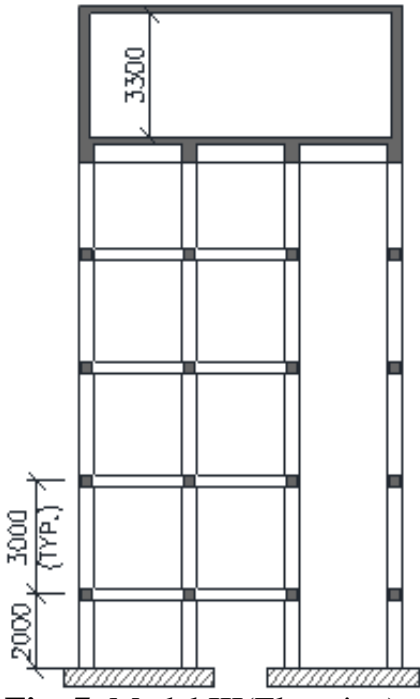

Fig -7: Model III(Elevation)

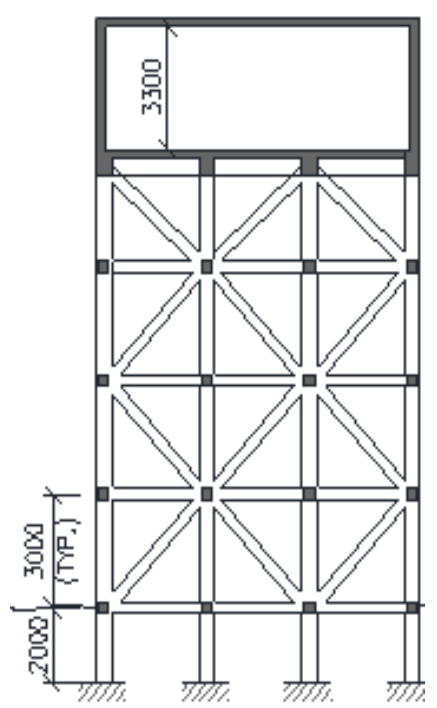

Fig -8: Model IV(Elevation)

Model I: Staging with conventional system having ties at $3 \mathrm{~m}$ $\mathrm{c} / \mathrm{c}$ along height

Model II: Staging with diagonal shear wall in plan

Model III: Staging with shear wall at corner

Model IV: Staging with diagonal bracing in elevation

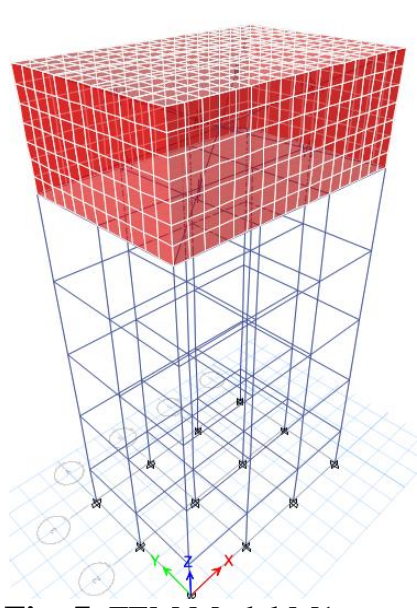

Fig -7: FEM Model M1

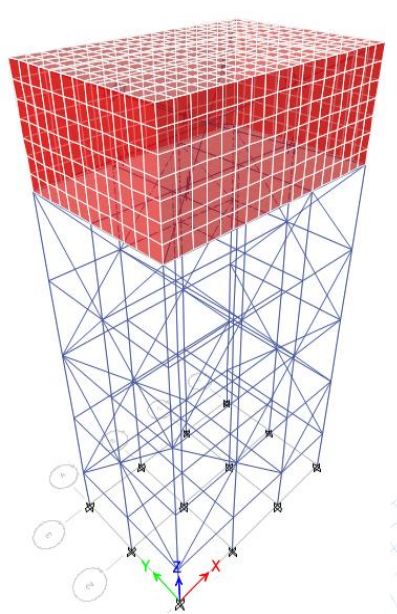

Fig -9: FEM Model M3

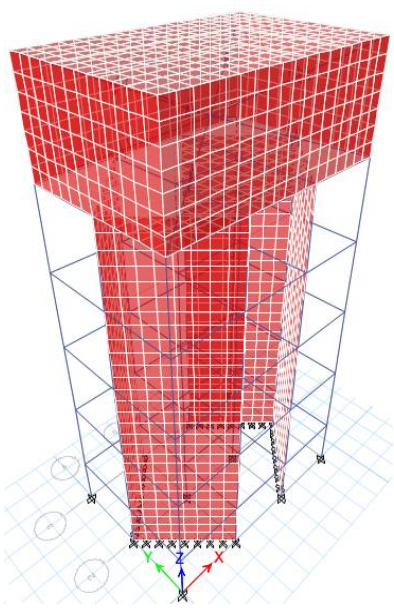

Fig -8: FEM Model M2

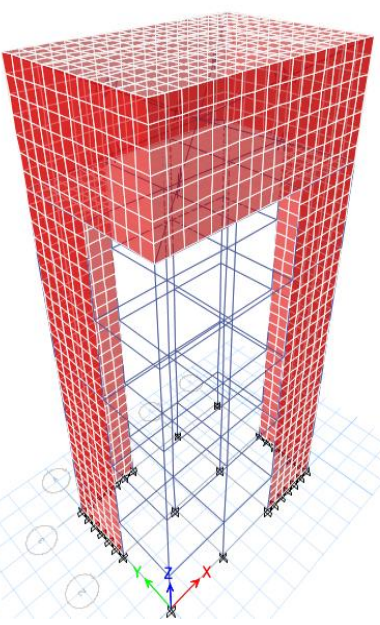

Fig -10: FEM Model M4 


\subsection{Analysis}

Equivalent static analysis considering hydrodynamic effect and response spectra analysis was carried out on the above selected models. For calculating the seismic weight of tank weight of empty container plus $2 / 3$ weight of staging is considered. Hydrodynamic forces were calculated considering spring mass model suggested by IS 1893:2002 part II. Tank is model in finite element software package ETABS. The walls are modeled as shell element with six degrees of freedom at each node. Beams and columns are modeled as frame element. The lateral forces considering impulsive and convective masses due to earthquake is lumped at mass centre of tank along both the principal directions. A rigid link is assumed from top of staging up to the mass centre of tank and lateral earthquake forces are lumped on rigid link in both the principal directions. For the present study CG of tank is taken as CG of empty container. Finally parameters such as base shear, displacement, moments and time period for the above four models are presented. The weight of different components of tank is shown in table

The parameters of spring mass model are (IS1893:2002) shown in table 1 below

Table -1: Parameters of spring mass model

\begin{tabular}{|c|c|c|c|}
\hline \multirow{2}{*}{$\begin{array}{l}\text { Sr. } \\
\text { No. }\end{array}$} & \multirow{2}{*}{ Parameter } & \multicolumn{2}{|l|}{ Value } \\
\hline & & Longitudinal & Transverse \\
\hline 1 & $\mathrm{mi} / \mathrm{m}$ & 0.35 & 0.55 \\
\hline 2 & $\mathrm{mc} / \mathrm{m}$ & 0.63 & 0.48 \\
\hline 3 & $\mathrm{hi} / \mathrm{h}$ & 0.38 & 0.38 \\
\hline 4 & $\mathrm{~h} * \mathrm{i} / \mathrm{h}$ & 1.28 & 0.8 \\
\hline 5 & hc/h & 0.52 & 0.59 \\
\hline 6 & $\mathrm{~h} * \mathrm{c} / \mathrm{h}$ & 1.2 & 0.85 \\
\hline 7 & $\mathrm{Cc}$ & 4 & 3.8 \\
\hline
\end{tabular}

Table2 -: Weight of different Components

\begin{tabular}{|c|c|c|c|c|c|}
\hline \multirow{2}{*}{$\begin{array}{l}\text { Sr. } \\
\text { No }\end{array}$} & \multirow{2}{*}{$\begin{array}{l}\text { Componen } \\
\mathrm{t}\end{array}$} & \multicolumn{4}{|c|}{ Weight (KN) } \\
\hline & & $\begin{array}{l}\text { Model } \\
\text { I }\end{array}$ & $\begin{array}{l}\text { Model } \\
\text { II }\end{array}$ & $\begin{array}{l}\text { Model } \\
\text { III }\end{array}$ & $\begin{array}{l}\text { Model } \\
\text { IV }\end{array}$ \\
\hline 1 & Cover slab & 405 & 405 & 405 & 405 \\
\hline 2 & Tank Walls & 798.75 & 798.75 & 798.75 & 798.75 \\
\hline 3 & Shear walls & NA & 1187.93 & 840 & NA \\
\hline 4 & Floor Slab & 270 & 270 & 270 & 270 \\
\hline 5 & $\begin{array}{l}\text { Floor } \\
\text { Beams }\end{array}$ & 146.3 & 129.09 & 146.3 & 146.3 \\
\hline 6 & Columns & 850.5 & 850.5 & 850.5 & 850.5 \\
\hline 7 & Tie Beams & 390.15 & 344.25 & 390.15 & 390.15 \\
\hline 8 & Braces & NA & $\mathrm{NA}$ & $\mathrm{NA}$ & 381.83 \\
\hline 9 & Water & 1523.6 & 1523.6 & 1523.6 & 1523.6 \\
\hline 10 & $\begin{array}{l}\text { Wt. } \\
\text { staging }\end{array}$ & 1240.6 & 2382.68 & 2080.6 & 1622.4 \\
\hline
\end{tabular}

\begin{tabular}{|c|l|l|l|l|l|}
\hline 11 & $\begin{array}{l}\text { Wt. of } \\
\text { Empty } \\
\text { container }\end{array}$ & $\mathbf{1 6 2 0}$ & $\mathbf{1 6 0 2 . 8}$ & $\mathbf{1 6 2 0}$ & $\mathbf{1 6 2 0}$ \\
\hline 12 & $\begin{array}{l}\text { Wt. of } \\
\begin{array}{l}\text { Container } \\
+1 / 3 \\
\text { staging }\end{array}\end{array}$ & $\mathbf{2 0 3 3 . 5}$ & $\mathbf{2 3 9 7 . 0 2}$ & $\mathbf{2 3 1 3 . 5}$ & $\mathbf{2 1 6 0 . 8}$ \\
\hline
\end{tabular}

\section{RESULTS AND DISCUSSION}

\subsection{Total Seismic Force}

Total seismic lateral force for different models are shown in table 3 below

Table3 -: Total Seismic Force (KN)

\begin{tabular}{|l|l|l|l|l|}
\hline $\begin{array}{l}\text { Total } \\
\text { Force }\end{array}$ & M1 & M2 & M3 & M4 \\
\hline FX $(\mathrm{KN})$ & 384.93 & 616.77 & 600.07 & 569.53 \\
\hline FY $(\mathrm{KN})$ & 385.32 & 676.25 & 659.55 & 629.01 \\
\hline
\end{tabular}

\subsection{Displacement and Base Shear}

Lateral displacement is found to be minimum for Model M2 Base shear is minimum in M1 since the seismic weight of model M1 is less than other three models. It should be noted that the lateral force (Base shear) in model M1 is about 40 to $50 \%$ less than other models, this is due to the fact that model M1 will have very light weight staging. Even though the lateral force is less the displacement in model M1 is far more than other three models.

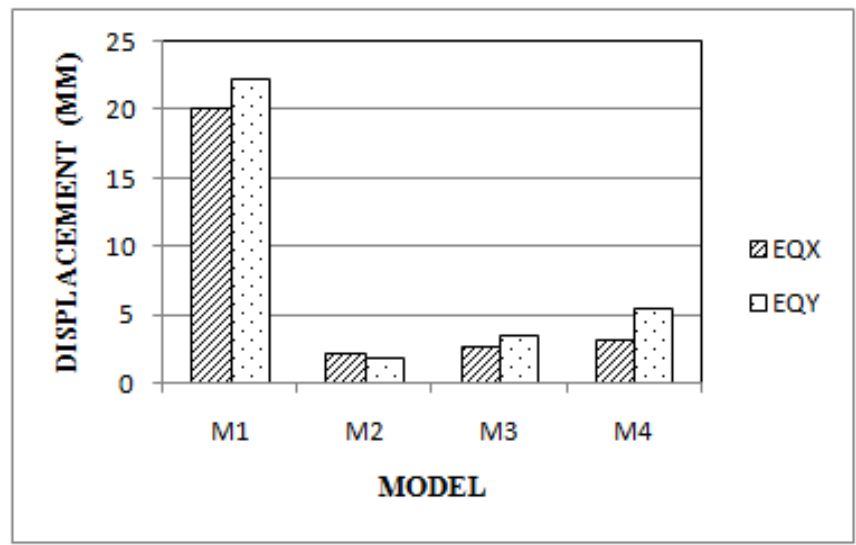

Fig -9: Lateral displacement

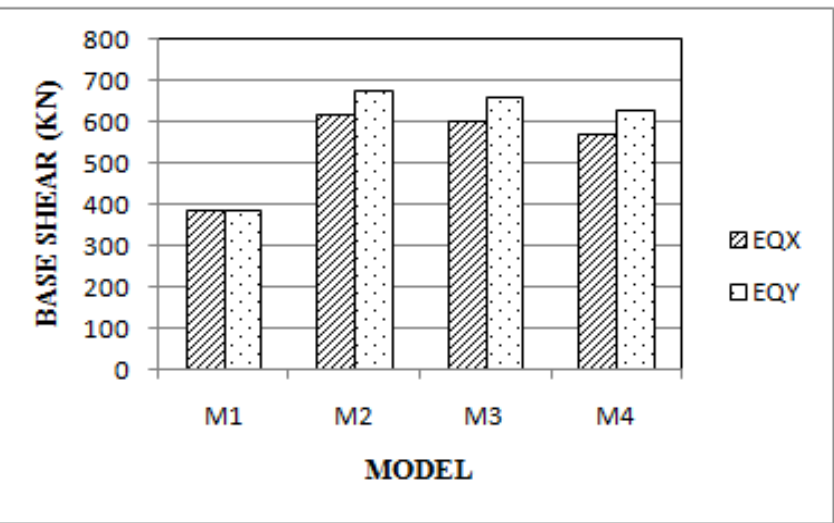

Fig -10: Base Shear 


\subsection{Maximum Column Forces}

The bending moment and shear force in both the principal direction is minimum in M2 in which shear walls are placed towards the central core.

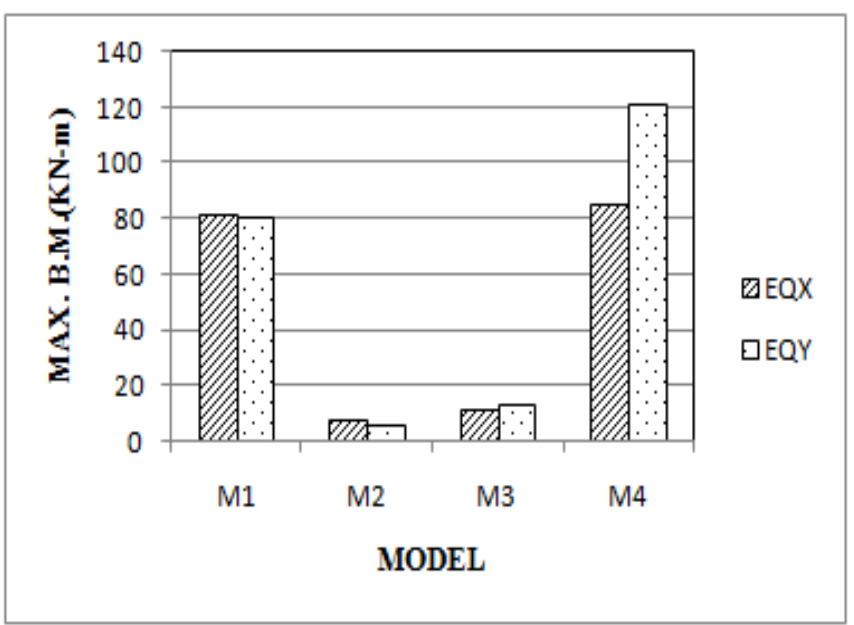

Fig -11: Maximum bending moment in column C1

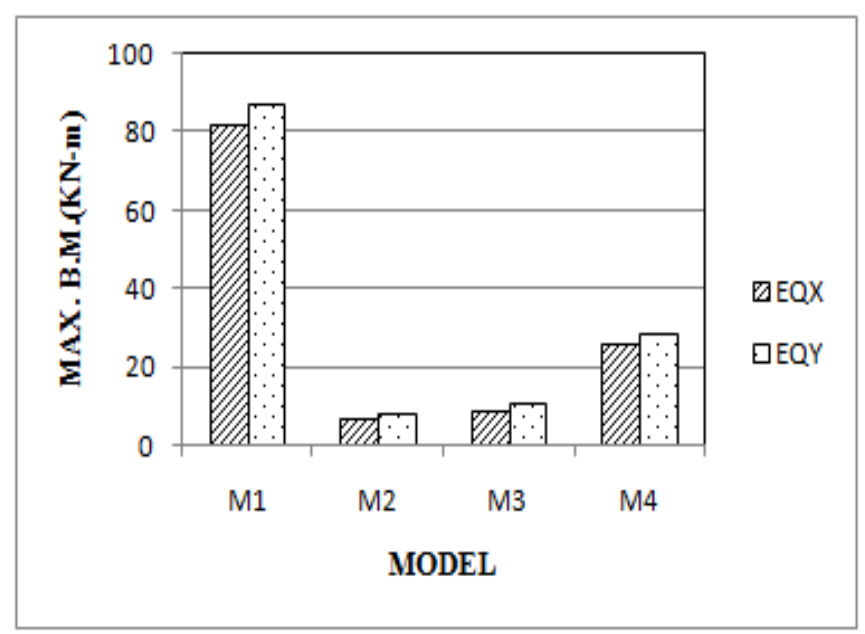

Fig -12: Maximum bending moment in column C2

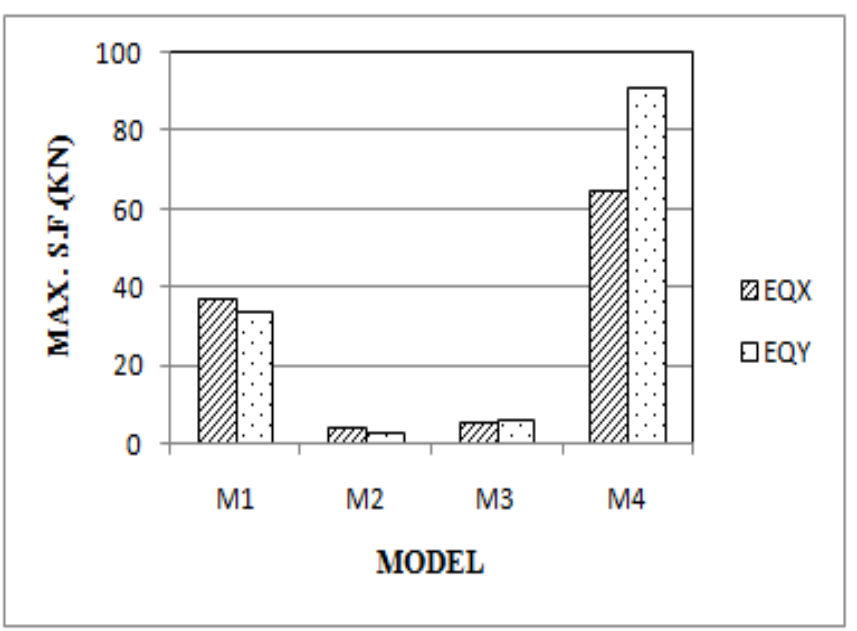

Fig -13: Maximum Shear force in column C1

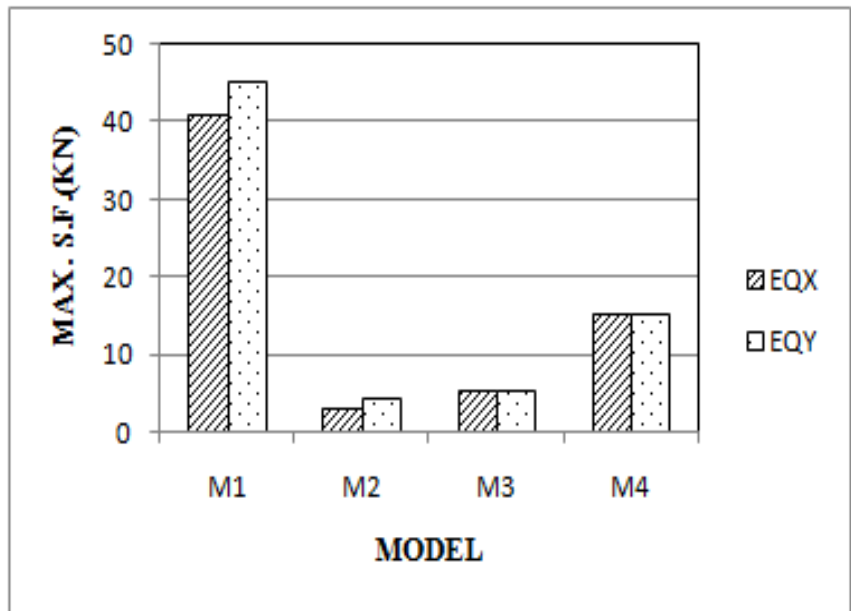

Fig -14: Maximum Shear force in column C2

\subsection{Time Period of Vibration}

Time period is found to be maximum for model M1 and minimum for model M2.

\begin{tabular}{|l|l|l|l|l|}
\hline \multirow{2}{*}{ Mode } & \multicolumn{4}{|l}{ Time Period (Sec) } \\
\cline { 2 - 5 } & M1 & M2 & M3 & M4 \\
\hline 1 & 1.349 & 0.315 & 0.408 & 0.506 \\
\hline 2 & 0.966 & 0.249 & 0.255 & 0.32 \\
\hline 3 & 0.625 & 0.119 & 0.131 & 0.191 \\
\hline 4 & 0.149 & 0.105 & 0.112 & 0.13 \\
\hline 5 & 0.14 & 0.083 & 0.084 & 0.101 \\
\hline 6 & 0.125 & 0.063 & 0.072 & 0.084 \\
\hline 7 & 0.1 & 0.059 & 0.066 & 0.081 \\
\hline 8 & 0.088 & 0.055 & 0.061 & 0.068 \\
\hline 9 & 0.075 & 0.054 & 0.054 & 0.066 \\
\hline 10 & 0.072 & 0.047 & 0.051 & 0.062 \\
\hline 11 & 0.066 & 0.041 & 0.041 & 0.058 \\
\hline 12 & 0.064 & 0.041 & 0.038 & 0.055 \\
\hline
\end{tabular}

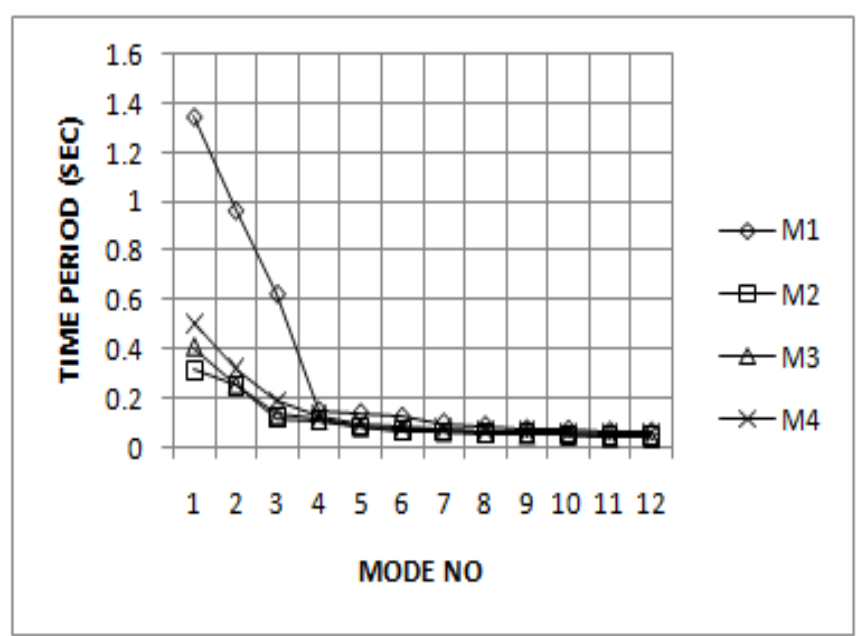

Fig -15: Time period of vibration 


\section{CONCLUSION}

The staging resistance under lateral loading can be significantly improved by providing shear walls located near the central core portion of staging. Lateral displacement for model M1 is 5 to 6 times the other three models, however the base shear for model M1 is minimum due to its reduced seismic weight. For peripheral and interior column the maximum forces ie bending moment and shear force is found to be minimum for Model M2. The columns provided along the periphery of building have been stressed more due to provision of bracings.

\section{REFERENCES}

[1]. George W. Housner, 1963 "The Dynamic Behaviour of Water Tank" Bulletin of the

Seismological Society of America. Vol. 53, No. 2, pp. 381387. February 1963

[2]. Jain Sudhir K., Sameer U.S., 1990, "Seismic Design of Frame Staging For Elevated Water Tank" Ninth Symposium on Earthquake Engineering (9SEE-90), Roorkey, December 14-16, Vol- 1.

[3]. Sudhir K. Jain and M. S. Medhekar, October-1993, "Proposed provisions for aseismic design of liquid storage tanks" Journals of structural engineering Vol.-20, No.-03

[4]. Sudhir K Jain \& Sajjed Sameer U, March1994,Reprinted from the bridge and structural engineer VolXXIII No 01

[5]. Sudhir K. Jain \& O. R. Jaiswal, September-2005, Journal of Structural Engineering Vol-32, No 03

[6]. M.K.Shrimali, R.S.Jangid "Earthquake Response Of Isolated Elevated Liquid Storage Tank"

[7]. IITK-GSDMA guidelines for seismic design of liquid storage tanks.

[8]. I.S 1893-2002 criteria for earthquake resistant design of structures.

[9]. IS: 3370 (Part II) - 1965 code of practice for concrete structures for the storage of liquids part ii reinforced concrete structures.

[10]. Dr. Suchita Hirde, Ms. Asmita Bajare, Dr. Manoj Hedaoo - 2011 "Seismic performance of elevated water tanks". International Journal of Advanced Engineering Research and Studies IJAERS/Vol. I /Issue I / 2011/ 78-87

\section{BIOGRAPHIES}

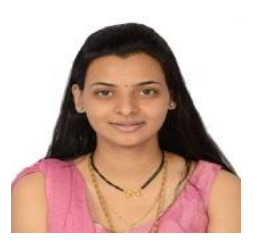

Nishigandha Rajendra. Patil' PG Student, Late G. N. Sapkal College of EngineeringNashik,Maharashtra,India Email: rutuja.patil73@gmail.com

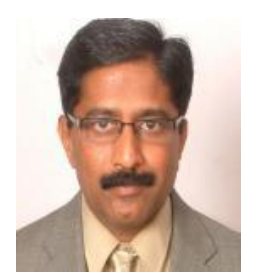

Dr. Rajashekhar S. Talikoti, Head of Department, Late G. N. Sapkal College of Engineering, Nashik, Maharashtra, India E-mail: rstalikoti@gmail.com 